\title{
PERANCANGAN SISTEM INFORMASI PEMBAYARAN SPP BERBASIS WEB MENGGUNAKAN NOTIFIKASI SMS GATEWAY (Studi Kasus : SMP Puspita Tangerang)
}

\author{
Erna Astriyani ${ }^{1}$, Meri Mayang Sari*2, Herman $^{3}$ \\ ${ }^{1,2}$ Program Studi Sistem Informasi Universitas Raharja, ${ }^{3}$ Program Studi Teknik Informatika \\ Email : ${ }^{1}$ erna.astriyani@ raharja.info, ${ }^{2}{ }^{2}$ meri.mayang@ raharja.info, \\ ${ }^{3}$ hermanputra123.hp@gmail.com
}

\begin{abstract}
Abstrak
Pembayaran SPP masih sering mengalami kendala seperti pendataan serta proses informasi pembayaran yang dilakukan secara manual dimana laporan rekaman masih menggunakan buku besar sehingga membuat pekerjaan menjadi terbengkala dan menghabiskan banyak waktu serta tenaga bagian keuangan dalam pencarian data siswa serta pengarsipannya. Pada era teknologi saat ini perlu adanya inovasi penggunaan teknologi dalam dunia pendidikan untuk membantu administrasi keuangan sekolah agar pendataan serta proses informasi Pembayaran berjalan dengan efektif dan efesien. Dalam jurnal ini akan membahas tentang perancangan sistem informasi pembayaran SPP berbasis web dan sms gateway menggunakan notifikasi sms gateway. Perancangan ini bertujuan untuk membantu bagian keuangan dalam mendata pembayaran SPP serta sebagai sarana penginformasian pembayaran kepada orang tua siswa/wali. Metode penelitian yang digunakan adalah metode SDLC jenis Waterfall. aplikasi ini membantu bagian keuangan dalam mendata pembayaran SPP dan orang tua/ wali mendapatkan informasi pembayaran setiap bulannya melalui notifikasi sms.
\end{abstract}

Kata kunci : Web, SMS Gateway, Pembayaran SPP

\begin{abstract}
SPP payments still often experience obstacles such as data collection and payment information processes that are done manually where recording reports still use a ledger, making work neglected and spending a lot of time and financial staff in searching student data and archiving. In the current technological era, it is necessary to innovate the use of technology in the world of education to assist the administration of school finance so that the data collection and information process of Payments run effectively and efficiently. In this journal will discuss about the design of web-based SPP payment information systems and sms gateways using sms gateway notifications. This design aims to assist the finance department in recording SPP payments and as a means of informing payments to parents / guardians. The research method used is the SDLC type Waterfall method. This application helps the finance department in recording SPP payments and parents / guardians get payment information every month through SMS notifications.
\end{abstract}

Keywords: Web, SMS Gateway, SPP payments

\section{PENDAHULUAN}

Perkembangan teknologi dan sistem informasi yang tepat akan menunjang kegiatan pendidikan pada lembaga atau institusi pendidikan. Suatu lembaga pendidikan memerlukan 
pengelolaan manajemen yang maksimal demi pelayanan dalam pemenuhan kebutuhan pendidikan masyarakat. Pengajaran yang dilakukan oleh guru terhadap siswa adalah bagian utama dari sekolah, selain proses belajar mengajar, terdapat aktivitas lain, yaitu proses administrasi keungan sekolah. Proses yang dimaksud adalah tindakan pengelolaan keungaan yang terdiri dari pencatatan data keungan Sumbangan Pembinaan Pendidikan (SPP) yang dibayar siswa tiap bulannya.

Proses pembayaran SPP pada SMP Puspita Tangerang masih dilakukan secara manual dan belum memiliki suatu sistem informasi berbasis Teknologi yang mengelola serta menangani data administrasi pembayaran SPP, sehingga menyebabkan kurang cepatnya pelayanan terhadap siswa dan keamanan data yang tidak bisa dijaga dan menimbulkan kehilangan data serta kesalahan pada proses pembuatan laporan. Selain itu jika siswa kehilangan kartu SPP petugas akan mengalami kesulitan mengetahui data pembayaran yang sudah dilakukan sebelumnya, karena petugas harus memeriksa lagi spreadsheet, buku harian dan buku besar yang tentunya tidak efisien waktu.

Berdasarkan pada persoalan yang dihadapi oleh SMP Puspita Tangerang perlu dibuat sistem informasi yang dapat mengatasi persoalan tersebut dengan memanfaatkan teknologi informasi terbaru yang sudah ada, untuk mengatasi permasalahan yang dialami serta dapat berkontribusi bagi peningkatan kinerja dari bagian TU. Oleh karena itu perlu adanya media sebagai jembatan informasi. Yang dimaksud dengan jembatan informasi ini merupakan pembuatan sistem informasi pembayaran SPP berbasis Web dan SMS Gateway yang digunakan oleh pihak sekolah untuk menyampaikan informasi kepada orang tua/wali siswa. Informasi yang dikirimkan melalui SMS berupa data pembayaran iuran wajib sekolah (SPP). Sistem informasi pembayaran SPP berbasis Web menggunakan sms notification diharapkan dapat membantu bagian keuangan dalam mengelola pembayaran SPP dan menjadi pengingat bagi siswa yang terlambat dalam pembayaran SPP.

\section{TINJAUN PUSTAKA}

\section{Pembayaran}

Menurut Evy (2019:54), Ada dua pengertian pembayaran yaitu pengertian secara sempit dan yuridis teknis. Pengertian pembayaran dalam arti sempit, adalah pelunasan utang oleh debitur kepada kreditur. Pembayaran seperti ini dilakukan dalam bentuk uang atau barang. Namun, pengertian pembayaran dalam arti yuridis tidak hanya dalam bentuk uang atau barang, tetapi juga dalam bentuk jasa, seperti jasa dokter dan lain-lain.

\section{SPP}

Menurut Ely (2014:80), SPP(Sumbangan Pembinaan Pendidikan) adalah biaya yang dibebankan kepada mahasiswa yang harus dibayar per semester selama menjadi mahasiswa. Besaran SPP juga beragam baik antara mahasiswa program diploma/sarjana dan program pascasarjana, maupun antara mahasiswa local dan mahasiswa asing.

\section{Web}

Menurut Beranda Agency dalam buku "Menggali Harta Karun Internet" (2010:10), menjelaskan bahwa World Wide Web (www) atau disebut dengan istilah web merupakan layanan yang sangat banyak digunakan dalam internet dimana terdiri atas kumpuan dokumen elektronik dari seluruh Negara. Setiap dokumen elektronik dalam web disebut sebagai halaman web (Web Page), yang dapat menyimpan teks, gambar, audio, dan video. Selain itu, halaman-halaman web biasanya tersambung ke dokumen-dokumen lainnya.

\section{SMS Gateway}


Menurut Wahana Komputer dalam buku "Mudah Membuat Aplikasi SMS Gateway dengan CodeIgniter" (2014:1), menjelaskan bahwa SMS Gateway adalah suatu platform yang menyediakan mekanisme untuk mengirim dan menerima SMS. SMS Gateway dapat berkomunikasi dengan perangkat lain yang memeiliki SMS platform untuk menghantar dan menerima pesan SMS dengan sangat mudah. Hal ini dimungkinkan karena SMS Gateway juga dibekali tampilan antarmuka yang mudah dan standar.

\section{METODE PENELITIAN}

Metode yang digunakan pada pengembangan perangkat lunak ini menggunakan waterfall. Menurut Yurindra (2017:41). Waterfall merupakan model yang membangun perangkat lunak berdasarkan Daur Hidup Perangkat Lunak (SDLC), yaitu model yang mempunyai struktur yang dimulai dari Perencanaan, Analisis, Design dan Implementasi. Seperti yang disajikan pada gambar 1.

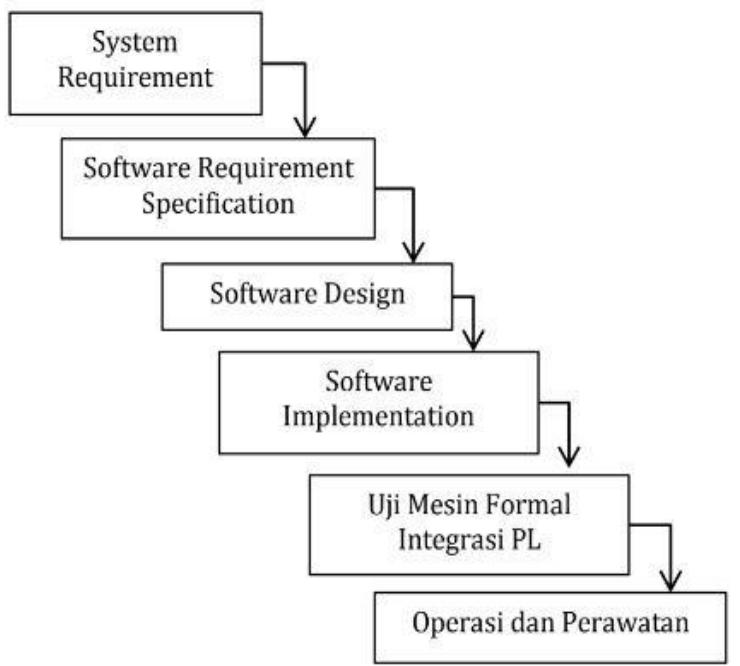

Gambar 1. Metode Waterfall

\section{Literature Review}

Banyak penelitian yang sebelumnya dilakukan mengenai sistem pembayaran SPP dari penelitian lain yang berkaitan. Dalam upaya mengembangkan dan menyempurnakan sistem tersebut diperlukan studi pustaka (literature review) sebagai salah satu dari penerapan metode penelitian yang dilakukan diantaranya yaitu:

1. Penelitian yang dilakukan oleh Moch. Mastur Bayhaqi (2011), yang berjudul "Perancangan Sistem Admiinistrasi Pembayaran Sekolah Pada SMK Global Tangerang Berbasis Web". Metode yang diusulkan pada penelitian ini menggunakan program Visual Paradigma for UML 6.4 untuk menggambarkan Use Case Diagram, Sequance Diagram, State Diagram, Activity Diagram,. Untuk membantu bagian keuangan dalam melakukan pekerjaan yang meliputi penginputan data siswa sampai dengan pembuatan laporan keuangan per periode. Dan system pengarsipan data yang lebih aman dan tidak tumpang tindih. Sistem ini diharapkan bias meningkatkan pelayananan dan kenyamanan terhadap para siswa SMK Global Tangerang yang melakukan transaksi pembayaran.

2. Penelitian yang dilakukan oleh Sylvia (2013), yang berjudul "Perancangan Sistem Informasi Pembayaran SPP Siswa Pada SMA Islamic Centre Tangerang". Metode yang diusulkan pada penelitian ini pemograman dirancang dengan aplikasi Macromedia Dreamweaver, XAMPP dan database MySQL. Belum adanya peringatan terhadap sistem apabila orang yang ingin melakukan tindak kejahatan atau memanipulasi data. Penelitian akan dikembangkan lagi dengan sistem yang dapat menghasilkan output secara cepat berupa 
kwitansi sebagai pergantian tanda bukti kartu iuran, agar menghemat biaya yang dikeluarkan pihak sekolah untuk cetak.

3. Penelitian yang dilakukan oleh Ahmad Juwaeni (2009), yang berjudul "Analisa Sistem Administrasi Sekolah Pada SMA Negeri 1 Pasar Kemis", pada tahun. Metode yang diusulkan pada penelitian ini menggunaan program Visual Basic 6.0. untuk membantu divisi keuangan, sistem yang diusulkan bertujuan untuk memudahkan tata usaha atau bendahara dalam mengelola administrasi sekolah. Program yang dibuat hanya masalah pembayaran SPP dan pendaftaran siswa baru saja. Dengan ini penelitian akan dilanjutkan dengan memasukkan pembayaran SPP dan Iuran Komputer.

Dari ketiga literature review yang ada, telah banyak penelitian mengenai pembayaran spp yang dilakukan dengan berbagai macam metode. Namun metode tersebut lebih terpusat kepada administrasi pembayaran. Tidak sampai dengan notifikasi sms sebagai sarana informasi kepada orang tua/wali siswa.

\section{HASIL DAN PEMBAHASAN}

Untuk dapat menggambarkan prosedur secara keseluruhan diperlukan beberapa tahapan analisa sebagai bentuk pengumpulan informasi guna mendapatkan model yang sesuai dengan kebutuhan dan mampu memberikan solusi dengan cepat secara efektif dan efisien, mulai dari tahapan pengumpulan informasi dan kebutuhan, analisa dokumen, merancangan hubungan antar dokumen sampai dengan merancanga model diagram database dan model rancangan sistem. Beberapa tahapan yang dimaksud sampai dengan model rancangan yang diciptakan dapat dilihat pada gambar berikut :

\section{Use Case Diagram Diusulkan}

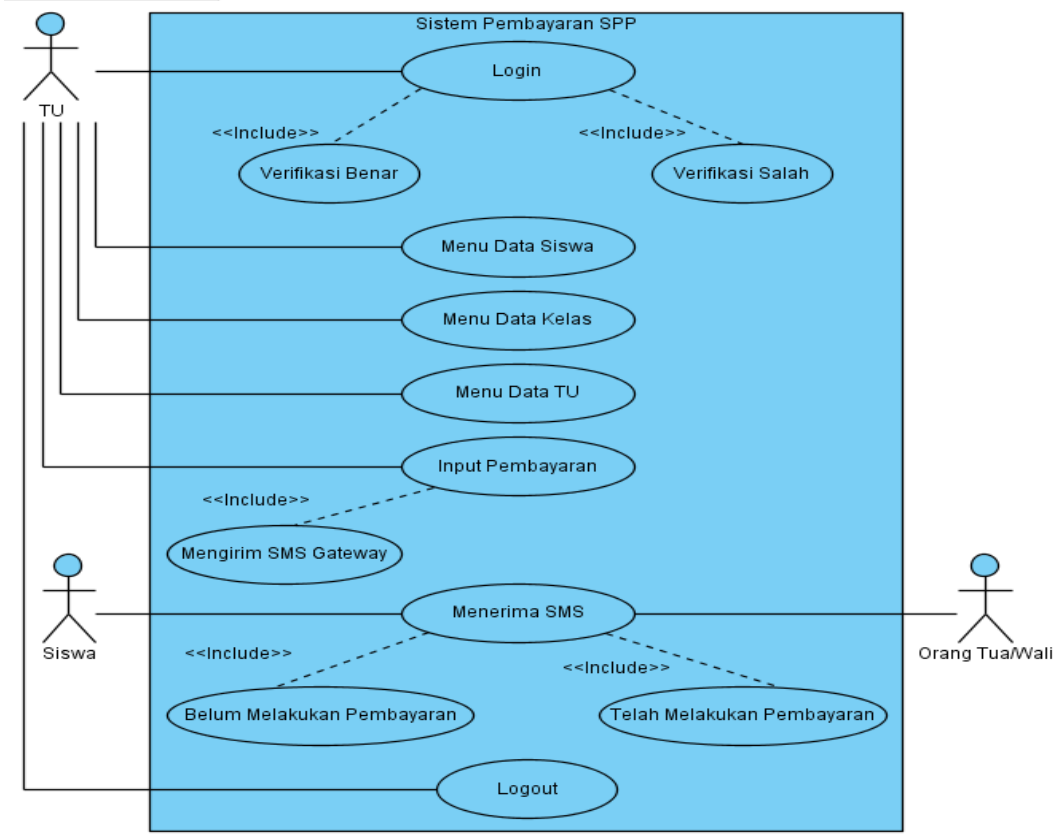

Gambar 2. Use Case Diagram

Pada usecase diagram terlihat bahwa admin melakukan login terlebih dahulu dengan memasukkan username dan password yang benar, melakukan akses pada menu data siswa (tambah, edit, dan hapus data siswa), menu data kelas (tambah, edit, dan hapus data kelas), menu data TU (tambah, edit, dan hapus data TU), melakukan input pembayaran disertai dengan 
mengirim notifikasi SMS kepada orang tua/wali dan siswa, siswa dan orang tua/wali menerima sms, admin log out jika telah selesai.

\section{Activity Diagram Diusulkan}

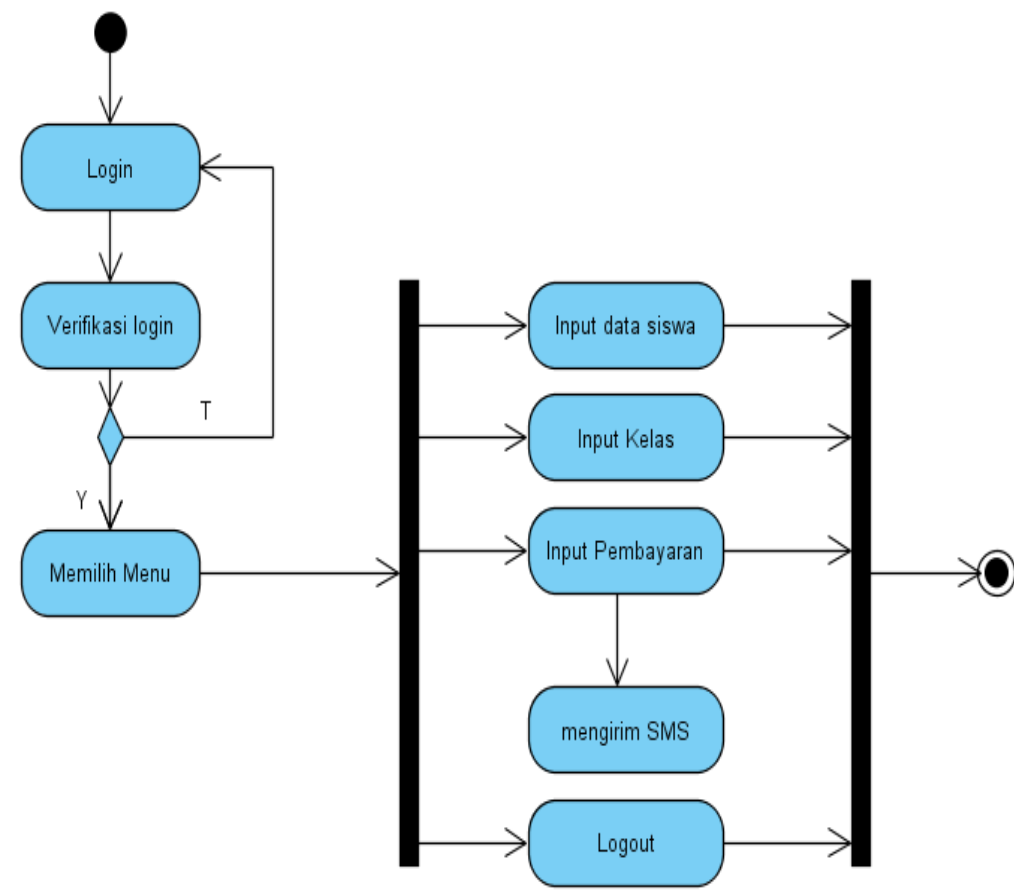

Gambar 3. Activity Diagram

Pada activity diagram, admin harus melakukan login terlebih dahulu dengan memasukkan username dan password yang benar dengan hak akses dapat menginput, melihat, menyimpan, mencetak laporan serta mengirim notifikasi SMS Gateway.

\section{Squence Diagram Diusulkan}

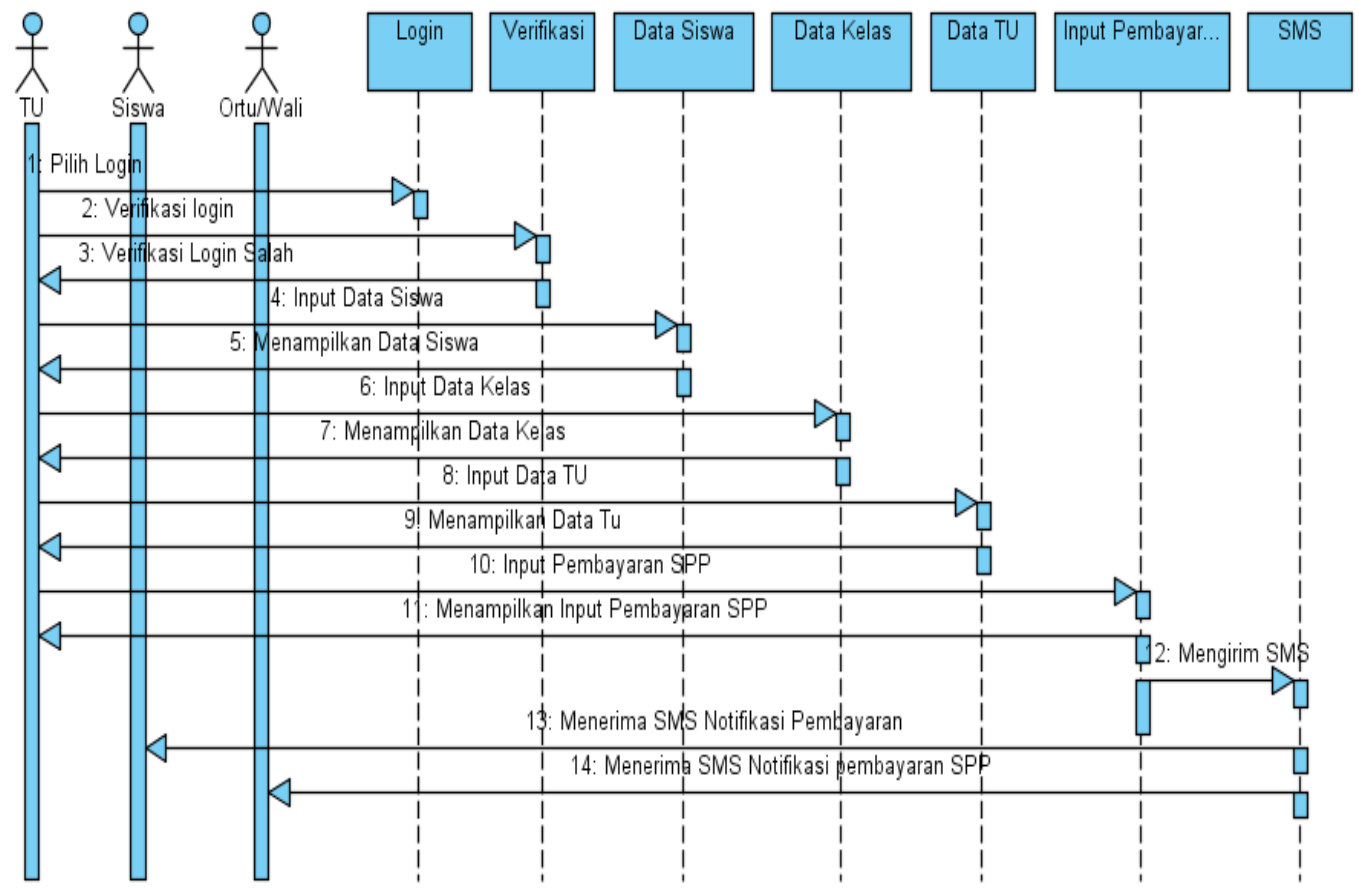




\section{Gambar 4. Squence Diagram}

Pada sequence diagram, Aktor I (TU) dapat melakukan login terlebih dahulu dengan memasukkan username dan password yang benar, setelah berhasil login, TU akan masuk ke menu dashboard. Selanjutnya, TU dapat menambah dan menapilkan data siswa, data kelas, data TU, data pembayaran dan mengirin notifikasi sms kepada siswa dan orang tua/wali siswa.

Aktor II (siswa), mendapatkan bukti pembayaran dan notifikasi sms telah melakukan pembayaran.

Aktor III (ortu/wali) mendapatkan notifikasi sms telah melakukan pembayaran.

\section{Desain Rancangan Program}

Desain rancangan sistem informasi pembayaran SPP Pada SMP Puspita Tangerang merupakan hasil dari implementasi perancangan sistem baru, diantaranya adalah :

\section{a. Tampilan Menu Login}

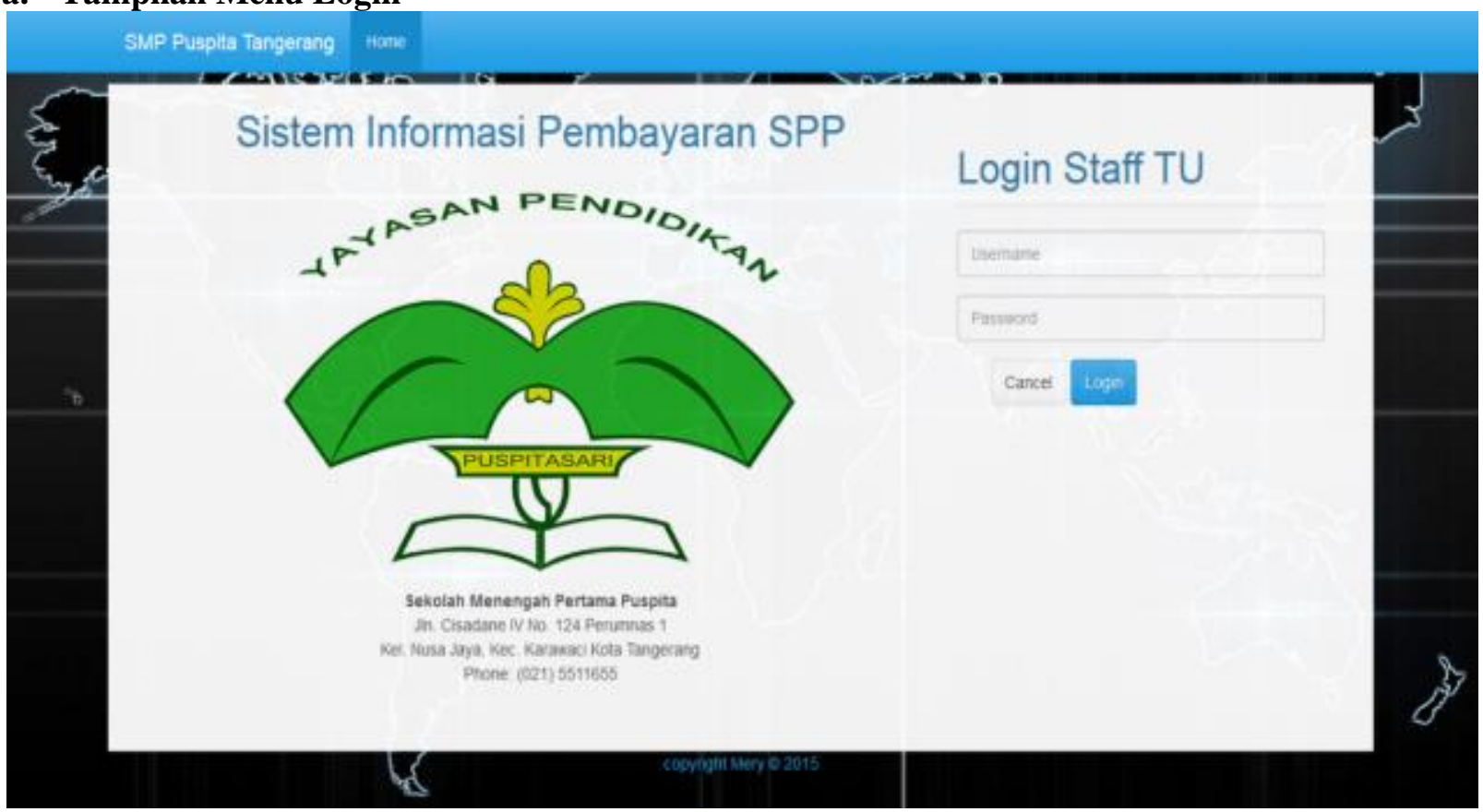

Gambar 5. Tampilan Menu Login

User dengan benar selanjutnya klik login dan setelah itu user dapat masuk kedalam sistem. Sedangkan kalau username dan password salah maka tidak akan dapat masuk kedalam sistem dan akan muncul tulisan bahwa username dan password yang anda masukkan salah.

\section{b. Tampilan Menu Data Siswa}




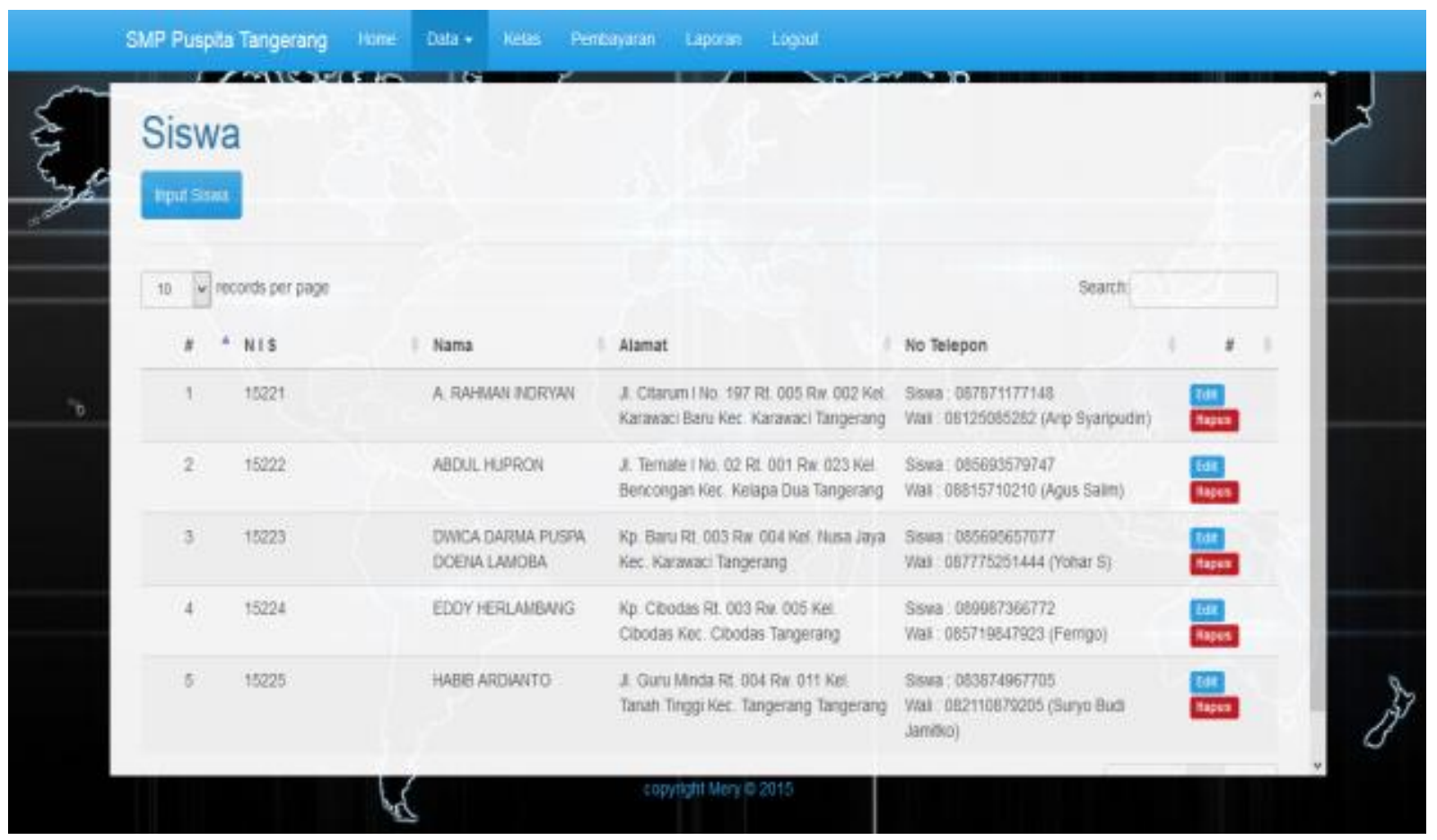

Gambar 6. Tampilan Menu Data Siswa

Halaman ini berfungsi untuk menampilkan data siswa berupa nis, nama, alamat dan no. telepon.

\section{c. Tampilan Menu Input Data Siswa}

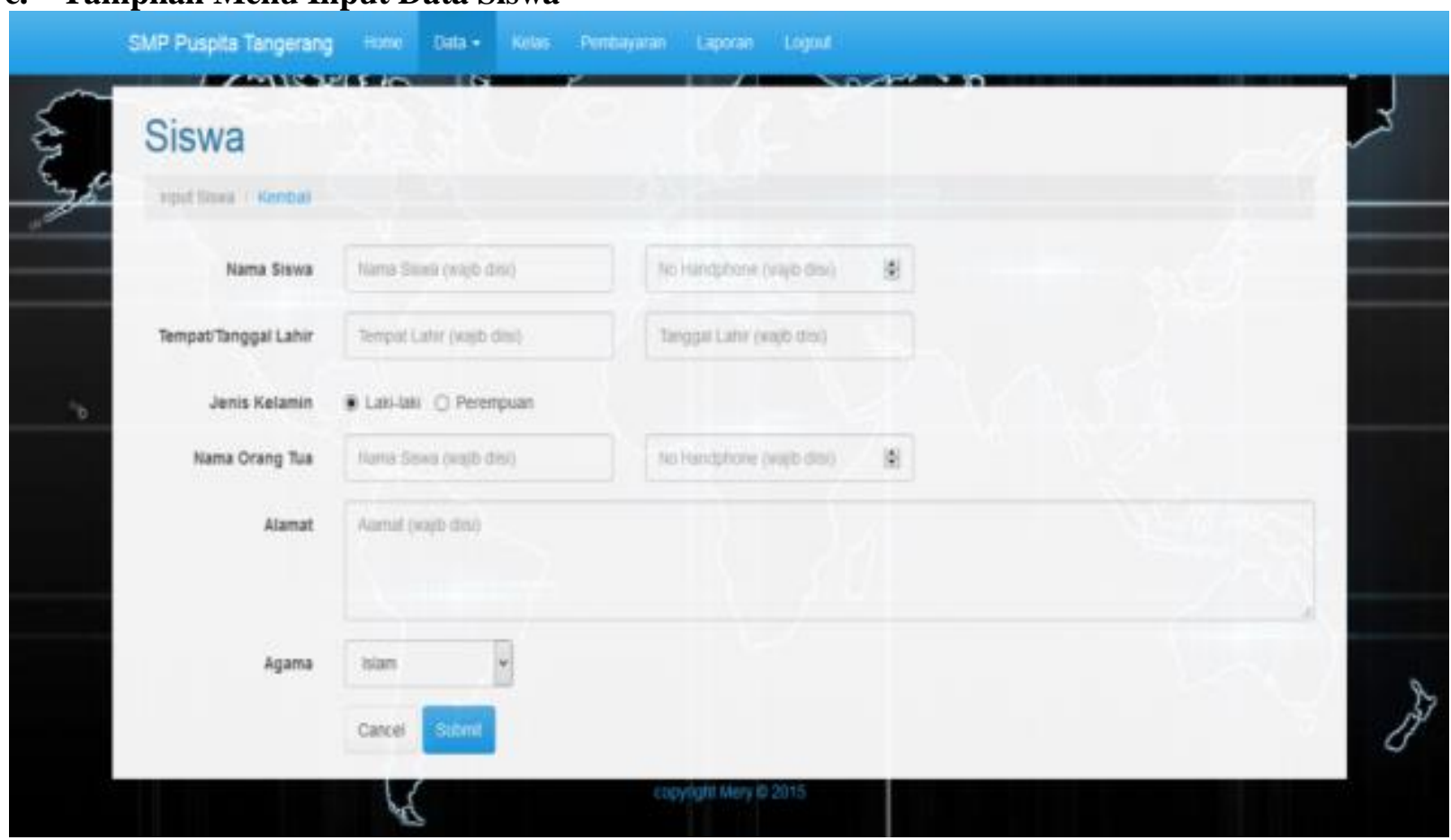

Gambar 7. Tampilan Input Data Siswa 
Halaman ini berfungsi untuk menampilkan input data siswa yang harus di input berupa nama siswa, tempat/tanggal lahir, jenis kelamin, nama orang tua/wali, alamat dan agama untuk keperluan sekolah dalam mengurus berkas siswa/I dikemudian hari.

\section{d. Tampilan Data Pembayaran}

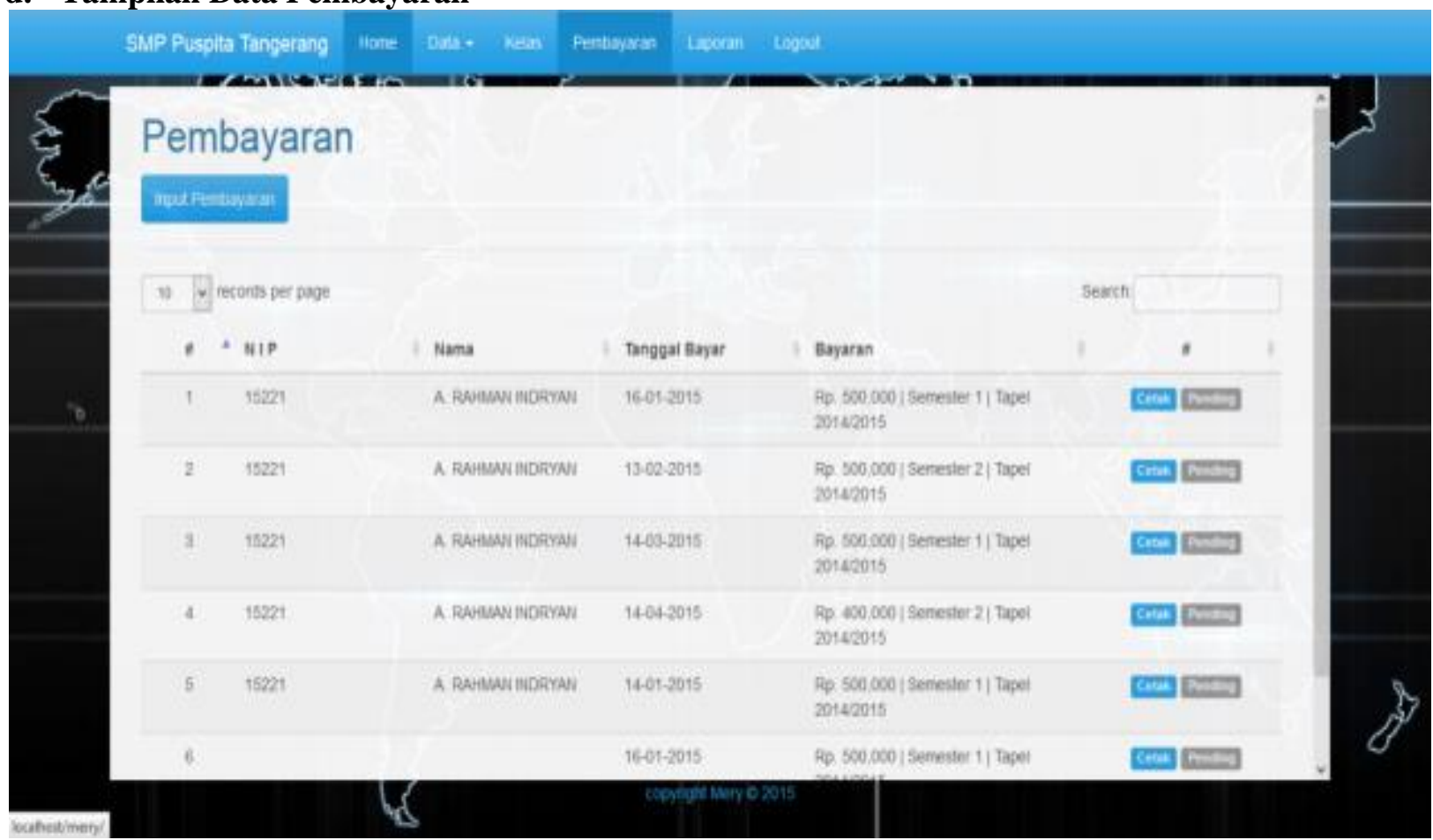

Gambar 8. Tampilan Menu Data Pembayaran

Halaman ini berfungsi untuk menampilkan data pembayaran yang dilakukan siswa serta langsung mengirimkan notifikasi ke no. telp orang tua / wali siswa setelah melakukan pembayaran.

\section{e. Tampilan Input Pembayaran}




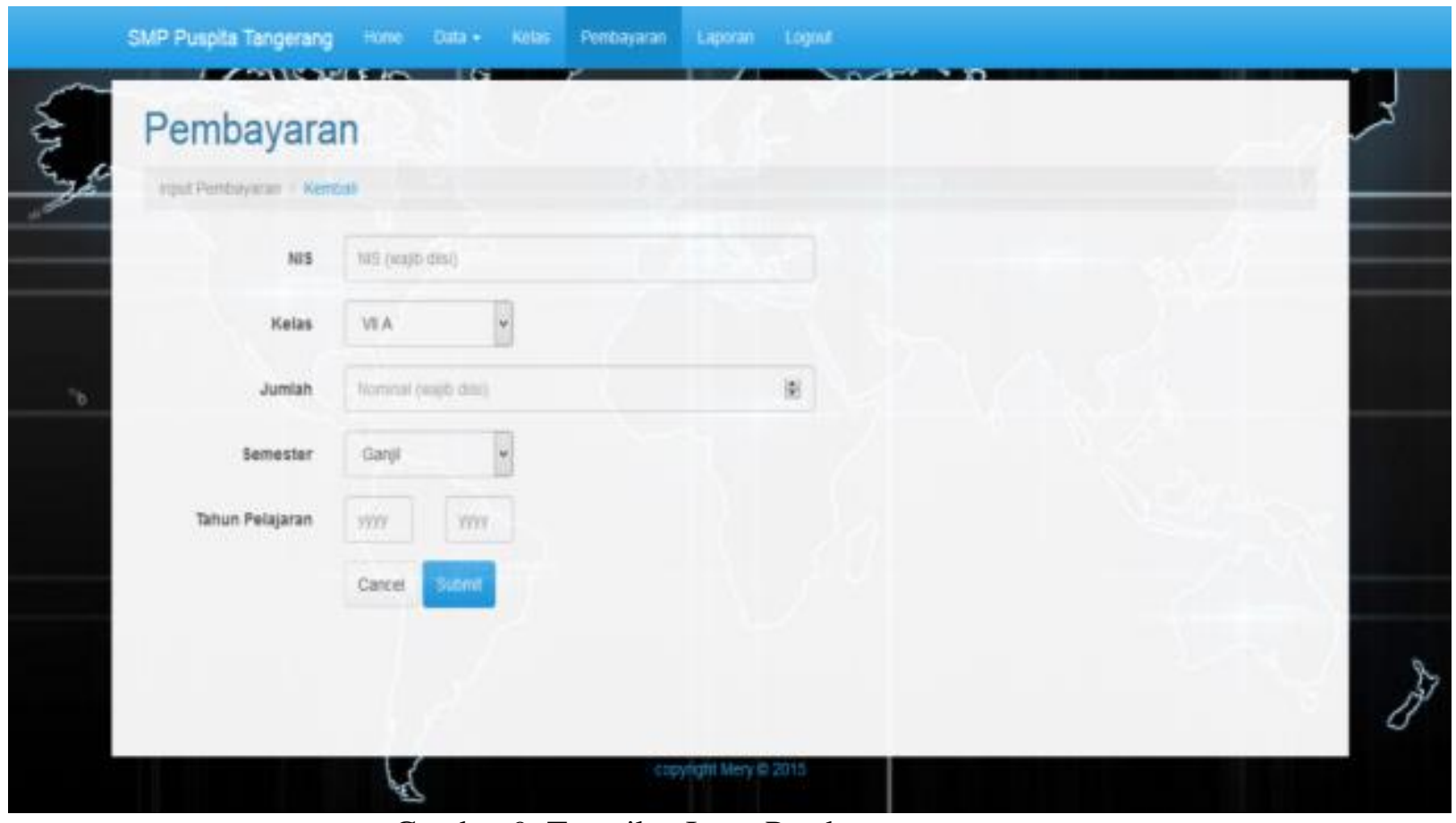

Gambar 9. Tampilan Input Pembayaran

Halaman ini berfungsi untuk menampilkan data input pembayaran sebelum melakukan pembayaran berupa nis, kelas, jumlah pembayaran, semester dan tahun ajaran .

\section{f. Tampilan Menu Laporan}

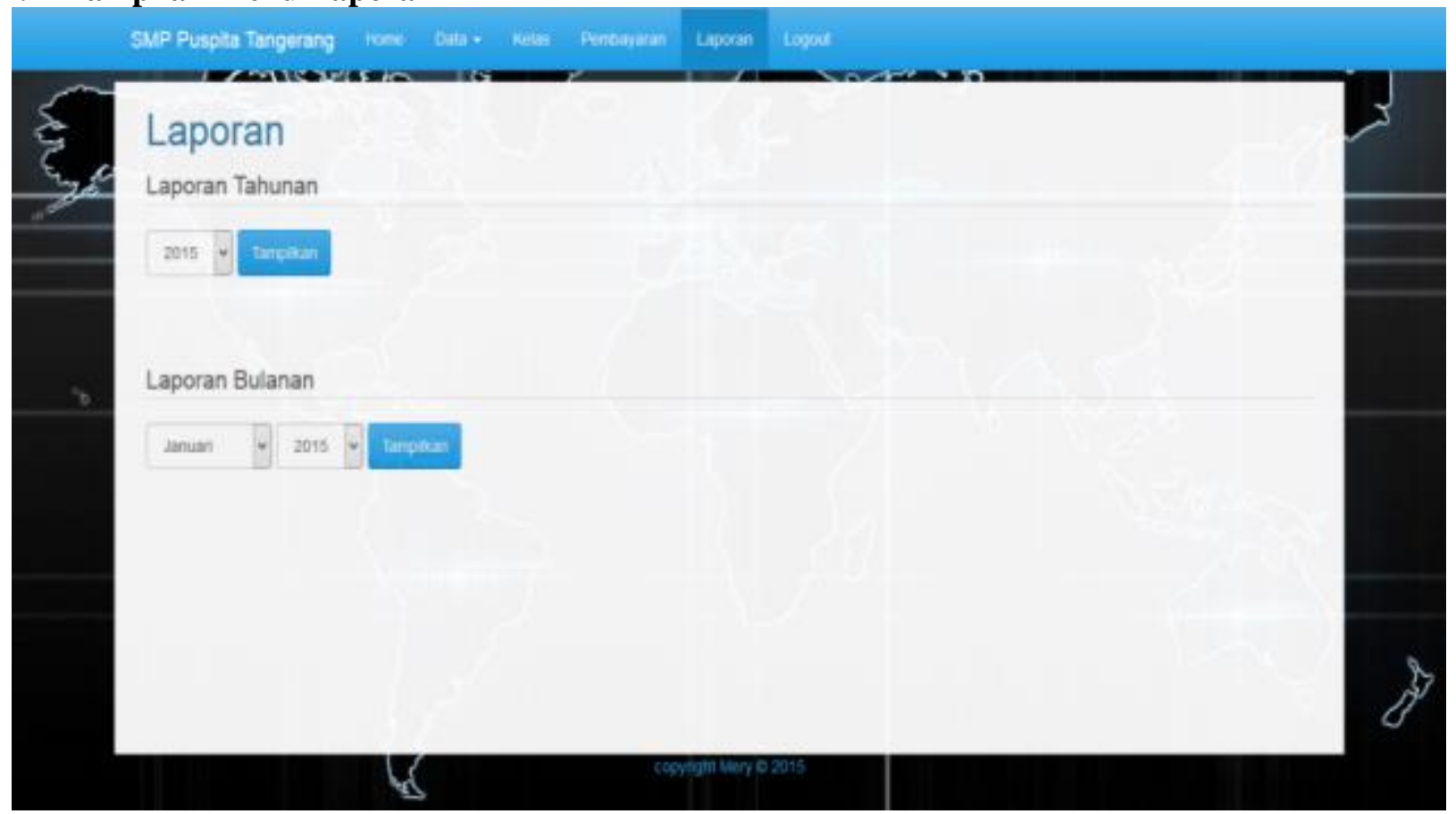

Gambar 10. Tampilan Menu Laporan

Halaman ini berfungsi untuk menampilkan data menu laporan tahunan dan bulanan sebelum dicetak untuk dilaporkan.

\section{g. Tampilan Menu Laporan Bulanan}




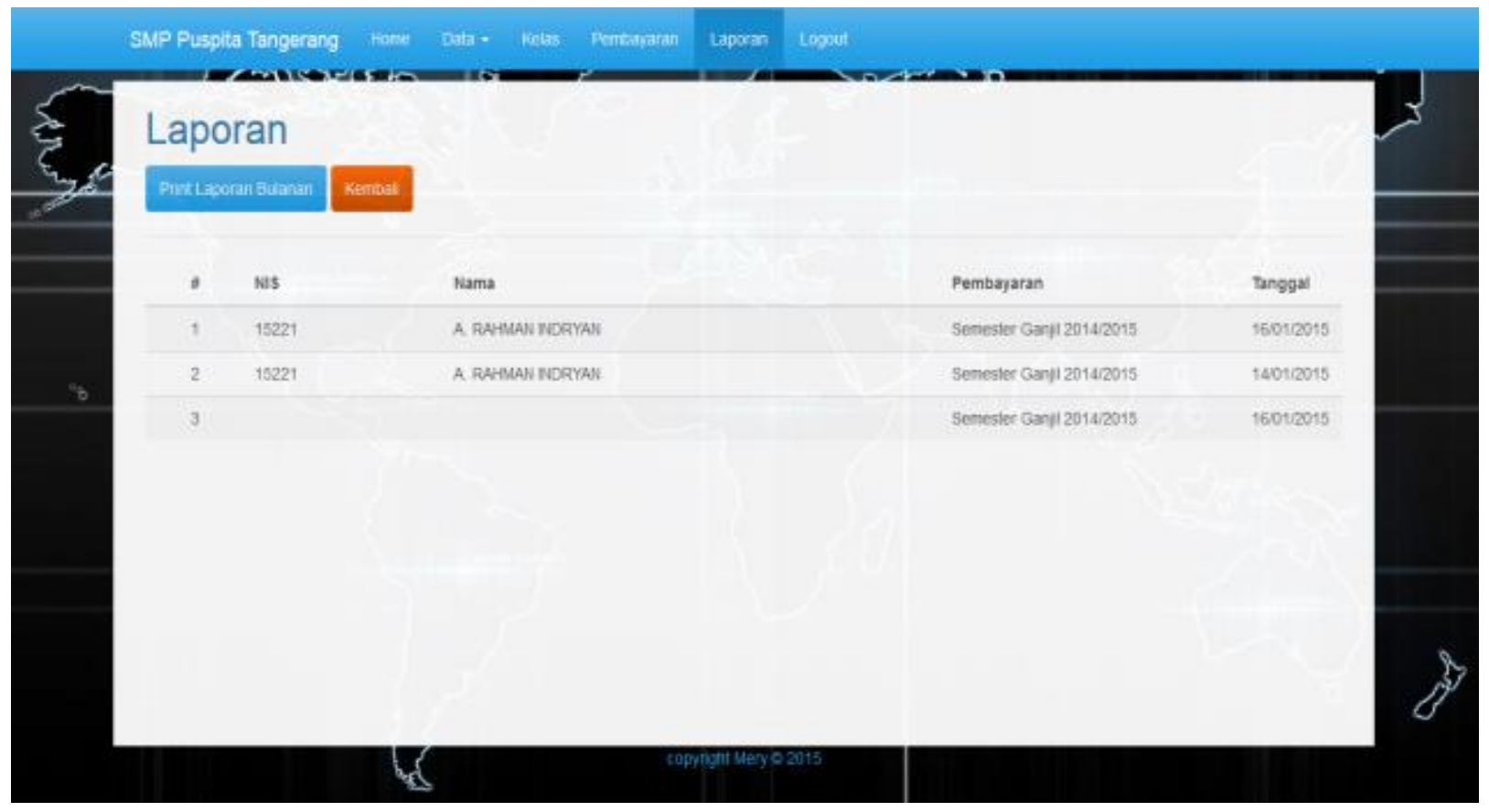

Gambar 11. Tampilan Laporan Bulanan

Halaman ini berfungsi untuk menampilkan data laporan pembayaran untuk satu bulan

\section{h. Tampilan Menu Laporan Tahunan}

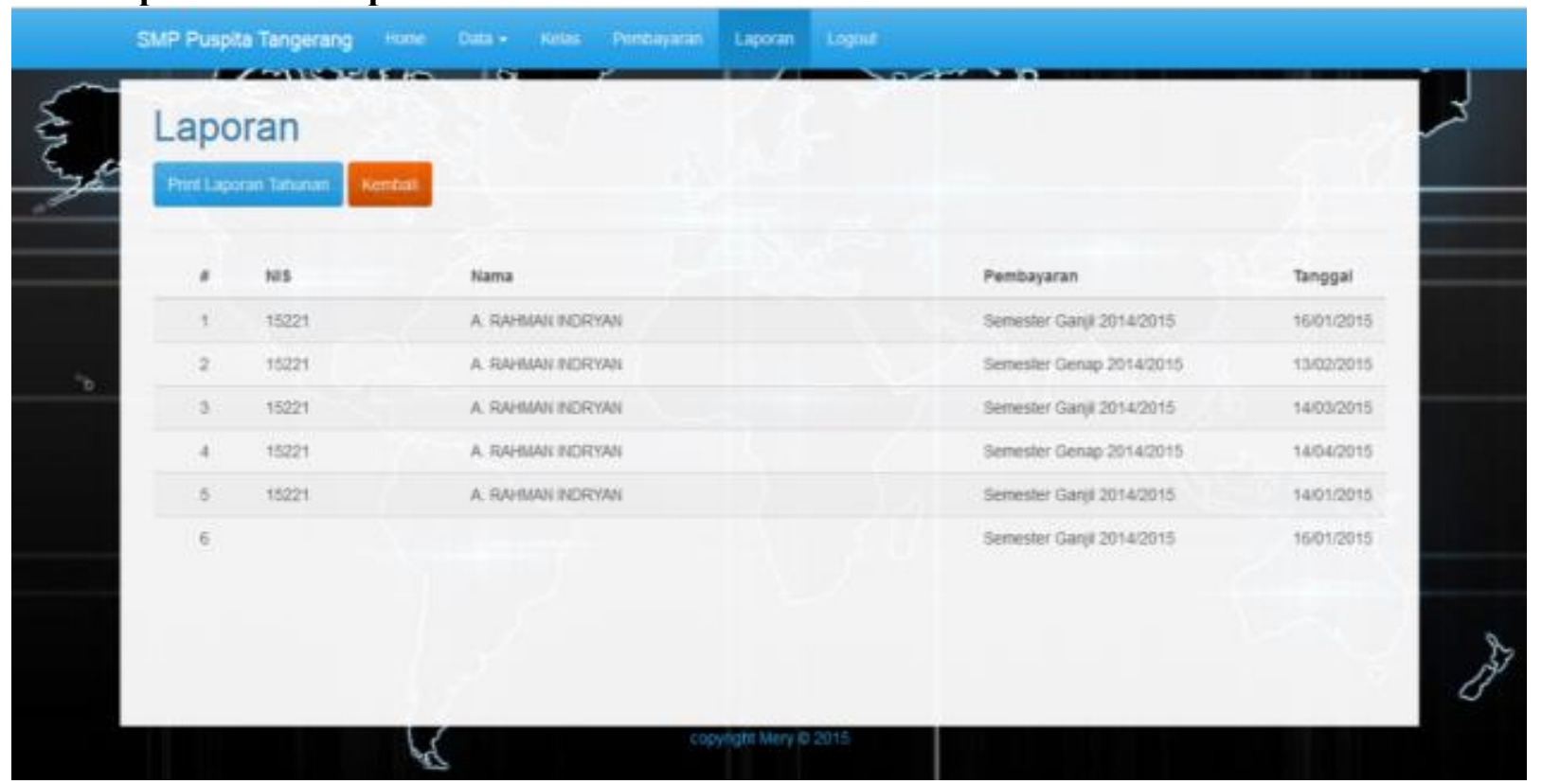

Gambar 12. Tampilan Laporan Tahunan

Halaman ini berfungsi untuk menampilkan data laporan pembayaran untuk satu tahun sebelum dicetak dan dilaporkan. 


\section{KESIMPULAN}

Dengan adanya sistem perancangan pembayaran SPP berbasis web dan SMS Gateway ini akan sangat membantu untuk mempermudah dan mempercepat pekerjaan dalam sistem pembayaran SPP dan SMS Gateway sebagai sarana informasi kepada orang tua/wali, sehingga orang tua/wali dapat memantau pembayaran putra-putrinya.

\section{SARAN}

Adapun saran yang dapat disajikan sebagai bahan pertimbangan bagi Sekolah antara lain

1. Dengan adanya sistem pembayaran SPP berbasis web ini diharapkan pihak sekolah dapat menggunakan sistem ini sebaik-baiknya dan dapat dikembangkan lagi agar menjadi sistem yang lebih baik

2. Agar selalu menggunakan proteksi file, karena hal ini sangat berguna untuk menghindari pemakai (user) lain yang tidak berkepentingan mengakses file tersebut

3. Setelah sistem dapat diterapkan dan dilaksanakan dengan baik, maka perlu dianalisis kembali sehingga tidak menutup kemungkinan untuk dilakukan suatu pembangunan sistem pembayaran yang baru dan yang lebih baik

\section{DAFTAR PUSTAKA}

[1] Savitri Gani, Evy. 2019. Perjanjian Terapeutik Antara Dokter dan Pasien. Sidoharjo: Uwais Inspirasi Indonesia

[2] Yuhefizar. 2009. Cara Mudah Membangun Website Interaktif Menggunakan Content Management System Joomla (CMS). Jakarta: PT. Elek Media Komputindo.

[3] Maulana, Sofyan. 2015. 5 Proyek Populer SMS Gateway. Jakarta: PT. Elex Media Komputindo

[4] Yurindra. 2017. Software Engineering. Yogyakarta: Penerbit Deepublish (Group Penerbitan CV Budi Utama)

[5] Siswanto, Ely. 2014. Good University Governance Prinsip dan Implementasi Dalam Penggalian Pendapatan. Malang: Gunung Samudera

[6] Wahana Komputer. 2014. Mudah Membuat Aplikasi SMS Gateway dengan CodeIgniter. Jakarta: PT Elex Media Komputindo 